\title{
Modeling of process of gear milling for definition of the intense deformed state in replaceable many-sided plates of a worm mill
}

\author{
E.V. Artamonov ${ }^{1}$, V.V. Kireev ${ }^{1, *}$, and V.A. Zyryanov ${ }^{1}$ \\ ${ }^{1}$ Tyumen industrial university, 625000, Tyumen, Volodarskogo Street, 38
}

\begin{abstract}
The tool equipment plays an important role in work of machine-building enterprises. One of the most important elements of equipment is the metal-cutting tool [1]. Replacement of the tool from HSS of steel on the cutting tool with use of WC-Co [2-7] sintered hard alloys gives increase in productivity and overall effectiveness of processing [811]. When the cutting ability of material of the tool increases, the universality of its application decreases therefore the most rational is comprehensive research approach which considers design of the tool the used WC-Co hard alloy. Design, production and testing of the toothed cutting tools, working off of the modes of cutting have to be carried out concerning a specific work piece and its material. When developing this kind of the tool it is necessary to consider features of WC-Co alloy as the cutting material, the cutting modes, destruction of the tool and other moments connected with its use. Influence of an initial contour on distribution of tension in the replaceable cutting many-sided plate. Results of calculation of the intense deformed state in a replaceable plate from the material WC-Co. Zones of stretching and compression are observed on the main cutting edge. Concentration of the dangerous stretching tension is located in a transitional zone between the direct side cutting edge to top as in this zone there is the greatest constraint of cutting. Respectively, the greatest destruction will happen in this zone. Important, the fact that in this part of the cutting edge there will be the biggest wear on a back surface. The analysis of isolines of distribution of tension showed that the stretching tension along a front surface of the replaceable cutting plate decreases because each replaceable cutting plate cuts off the part of material. First, work is entered by the made narrower cutting plate which cuts off metal an upper part of the cutting plate, and then the underestimated cutting plate which works with the side cutting edges works. As a result of the conducted researches it was established that with the progressive scheme of cutting in comparison with the standard scheme of cutting at which the initial profile of the making rail is made on DIN3972 at gear milling, dangerous tensile stresses in the cutting hardalloy plates significantly decrease.
\end{abstract}

\footnotetext{
*Corresponding author: kireevvv@tyuiu.ru
} 
To process to a shaping of cogwheels and also increase in productivity and firmness of the tool was devoted a set of scientific works. In them conducted tool researches depending on different factors: in the field of cutting process kinematics, influence on firmness of gear-cutting tools, the geometrical and design data of gear-cutting mills, parameters of the modes of cutting, schemes of cutting by gear-cutting mills which are characterized by a combination of the direction of giving [1], technical condition of the metal-cutting equipment, incision methods in the processed preparation, material of the tool and preparation, availability or lack of the greasing cooling liquid, the requirement to accuracy and quality to cutting process is analyzed and also influence on firmness of the tool depending on single-pass or multipass processing, especially in connection with emergence of gear-milling machines with numerical program control, adaptive management of cutting process is considered. In researches of process of a shaping it is reflected that the firmness of the gear-cutting tool is affected substantially by the sizes of the cut-off layers. The sizes of the cut-off layers affect wear of each tooth of a mill separately and in general on the cutting tool, power of cutting and torque and also serves as an obstacle for the choice of the modes of cutting.

These conclusions is confirmed by researches of face and cylindrical milling which show that the sizes of the cut layer (length and thickness) at the time of incision and its exit from a cutting zone with preparation, under equal conditions, determine forces of cutting and wear of teeths of a worm mill. The results of correction of a profile and height of teeths of the tool of worm type executed for the purpose of alignment of the distributed load of them and also a research in the field of change of an initial profile of the making rails in which for increase in firmness of the cutting teeths to decrease in forces of cutting and the sizes of the cutting-off layers led to decrease in wear of the cutting teeths of a worm mill. Proceeding from it, problems of complex optimization of parameters of milling of cogwheels are solved taking into account a condition of the metalworking machine, the cutting tool and the processed preparation. The tool equipment plays an important role in work of machine-building enterprises. One of the most important elements of equipment is the metal-cutting tool [2]. Replacement of the tool from HSS of steel on the cutting tool with use of WC-Co [3-8] sintered hard alloys gives increase in productivity and overall effectiveness of processing [9-12]. Comprehensive research approach which considers design of the tool the used WC-Co hard alloy that is rational the condition has to be considered that the cutting ability of material of the tool increases, the universality of its application decreases. Design of the tool, production of a prototype, testing, selection of the modes of cutting have to be carried out concerning a specific work piece and its material. When developing this kind of the tool it is necessary to consider features of the cutting WC-Co alloy material, the cutting modes, destruction of the tool and other factors relating to its operation. It was necessary to make researches of processes of loading, tension, the nature of destruction and durability of replaceable hard-alloy plates for performance of objectives by method of imitating modeling with use of the Compass-3D programs and a finite element method in ANSYS. The research of influence of geometry of the cutting plate from WC-Co hard alloy on their deformed state in the plane of a descent of shaving will help to define influence of distribution of tension in a plate under identical operating conditions of the tool (the cut module, quantity of teeths of a wheel and giving of the tool) and also will help to define zones of the greatest deformations on a front surface in the shaving descent plane.

An integrated approach to the solution of problems is the most rational, connected with design of the hard-alloy cutting tool it when the cutting ability of material of the tool increases, the versatility its applicability decreases. Design, production and testing of tools of worm type, selection of the rational modes of cutting have to be carried out concerning a specific work piece and its material. When developing metal-cutting tools made of WC-Co 
of alloy it is necessary to consider features of the cutting material, connected with its use i.e. the cutting modes, wear of the tool and other moments. It is reasonable to design the fine-module tool in the form of a design which is completely made of hard alloy. Manufacture integral disk shavers to the module of $0.8 \mathrm{~mm}$, gear-planing cutters, worm mills, to $1.5 \mathrm{~mm}$, disk modular mills up to $1 \mathrm{~mm}$, Mounted and tail pinion cutters up to 1.5 $\mathrm{mm}$ and manual modular mills make with crowns of WC-Co hard alloy and other alloys. At design of integral hard-alloy tools it is necessary to consider a possibility of placement of preparation from hard alloy in shape, close to the sizes of the ready tool and with the minimum admissions on processing. Length of the metal-cutting tool should not exceed repeatedly its diametrical size, width of an edge fillet of the tool is no more than $3 \mathrm{~mm}$, and their external outside has to be conic with a corner $5-10^{\circ}$ on the party. It is also important to consider technical requirements of rational work of diamond grinding wheels when developing the composite carbide tool. Grinding wheels lose ability to cutting over time and strongly wear out because of grinding of steel parts of the tool. Therefore the design features and geometrical parameters of the cutting part of the tool from sintered hard alloys ground by diamond wheels have to be chosen so that to exclude contact of a grinding wheel with the holder of the tool and the body multiple-blade tools during grinding, honing and finishing. Therefore front and back surfaces of a plate have to be located over the holder of a cutter, plug-in knives or the body of the tool at a size no more than 0.15 thickness of hardalloy platinum. Back corners: $a \mathrm{k}$ on the holder or on body tooth, an on a plate from hard alloy and $\alpha \varphi$ on a facet have to be different; usually accept $\alpha \pi=\alpha \varphi+\left(2.3^{\circ}\right)$ and $\alpha \mathrm{k}=\alpha \mathrm{n}+$ $\left(2.3^{\circ}\right)$. For receiving a qualitative surface it is necessary to provide an exit of a diamond wheel during processing consider free sites of the body at design or change diameter of the body on the site behind plates from WC-Co alloy. Behind plates in the body make technology grooves of WC-Co alloy. In that case when in addition to ground plates from WC-Co alloy it is necessary to make operational development of responsible surfaces of the tool. For reduction of an expense of diamond wheels, the drawing of the tool has to provide finishing on facets which sizes are established on the basis of specific conditions of processing.

Calculation hard-alloy significantly does not differ from calculation of similar tools from HSS alloy. Calculations of profiles of tools are made of hard alloy with use of the known techniques, except for calculation of new designs of the tool. At design of the national teams and compound gear-cutting tools, if necessary, it is necessary to calculate durability and reliability of fastening of the cutting elements from WC-Co sintered hard alloys. In addition to calculations of durability it is necessary to calculate thickness of cuts with the different cutting tooth edges. The analysis of two schedules of cross-section of the cut layers for the standard scheme of cutting at which an initial profile of the making rail is made on DIN3972 and the progressive scheme is provided in Articles [13-15, 18, 19]. From this the following conclusions are drawn: at a standard initial profile of the making rail loading of the cutting elements gradually increases to the middle of gear milling, and then decreases by the end, and at making the rail made on DIN3972 the big cut-off layers are in the beginning of process of cutting. In this case distribution of loads of the cutting elements in the progressive scheme is more homogeneous that is positive result for the tool the equipped WC-Co hard alloy; During the operation of the tool with the making rail made according to the progressive scheme of cutting the cut-off layers decreases in comparison with a profile of the making rail made on DIN3972. The maximum cross-sectional area of the cut-off layer for a full-height mill is $2.85\left[\mathrm{~mm}^{2}\right]$, and for progressive $1.9\left[\mathrm{~mm}^{2}\right]$. Reduction of cross-section (and, respectively, and loads of the cutting plates from WC-Co alloy) also reduces wear of the cutting edges of teeth because of reduction of constraint of cutting; in the progressive scheme of cutting teeth No. 3 and No. 4 are more active, and teeth No. 2 and No. 5 are almost not loaded in comparison with the full-height scheme. 
Throughout article [16-17] the research for calculation of the intense deformed condition of the replaceable cutting plates with the full-height and progressive scheme of cutting was conducted.

The experimental task of improvement of a final and element grid and influence of quantity of elements was carried out to grids on results of tension in WC-Co alloy with use of the program of the final and element analysis of ANSYS. Further in the program conditions only of those moments when during process of cutting the biggest areas of the cut-off layer at different profiles of the making rail were observed registered. It is necessary the threedimensional break model on a final and element grid for a possibility of application of such method of the decision.

To apply the finite element method (FEM), the optimization task of creation of final and element model with an optimum density of a final and element grid was solved. For this purpose in the interface of the ANSYS program for a start the model was "broken" into final elements in the mode which reduces mistakes at creation of a final and element grid. In a consequence of work calculation results of the intense deformed state (IDS) in WC-Co sintered hard alloys are shown.

For introduction, the correct conditions which I will describe the provision of WC-Co hard alloy in the body of the tool it is necessary to use properties of material, coefficient of the Punch and Jung's module, the dispersed loading on a front surface of a descent of shaving and a condition which imitate fixing of WC-Co hard alloy from movement which I arise in the course of cutting.

Cut off sites by mill teeths a front surface of a plate with the making rail made on DIN3972 (Fig. 1).
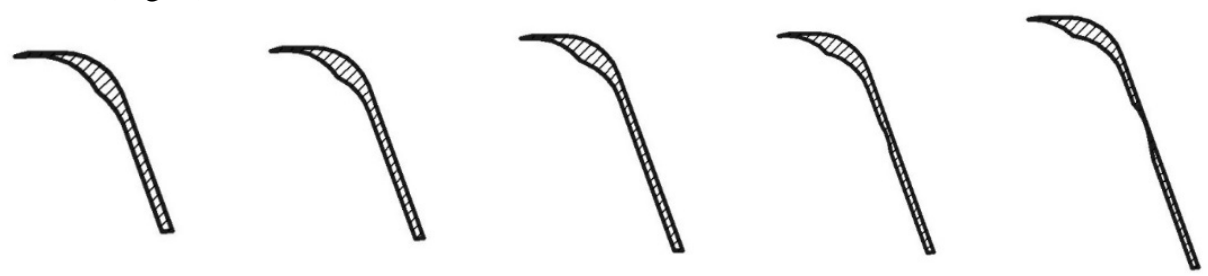

Fig. 1. The cut-off layers for the tool from the making rail made on DIN3972

Cut off sites by mill teeths a front surface of a plate with the making rail made on the progressive scheme of cutting (Fig. 2).
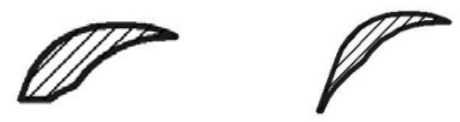

The made narrower contour e1
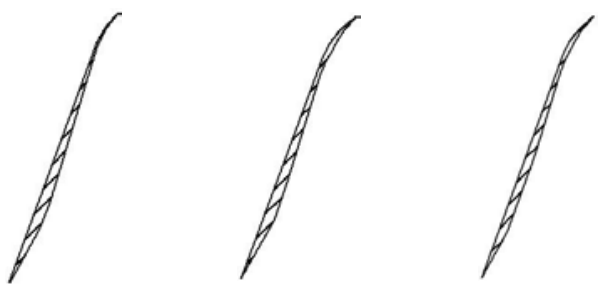

The underestimated contour e2

Fig. 2. The cut-off layers

The received images of color gradation of tension ${ }_{\sigma 1}$ for WC-Co hard alloy, with the making rail made on DIN3972 are shown. On the cutting edges of a plate there are zones of stretching and a zone of compression. Concentration of tensile stresses is in a zone where the vertex cutting edge and the entrance cutting edge is joined. In this area on a front 
surface holes thereby will be formed reducing durability of the cutting edge that leads to difficulty to formation of shaving. Respectively the greatest destruction on front and back surfaces will be happens in this zone as in this area the biggest constraint of cutting is observed (Fig. 3a).

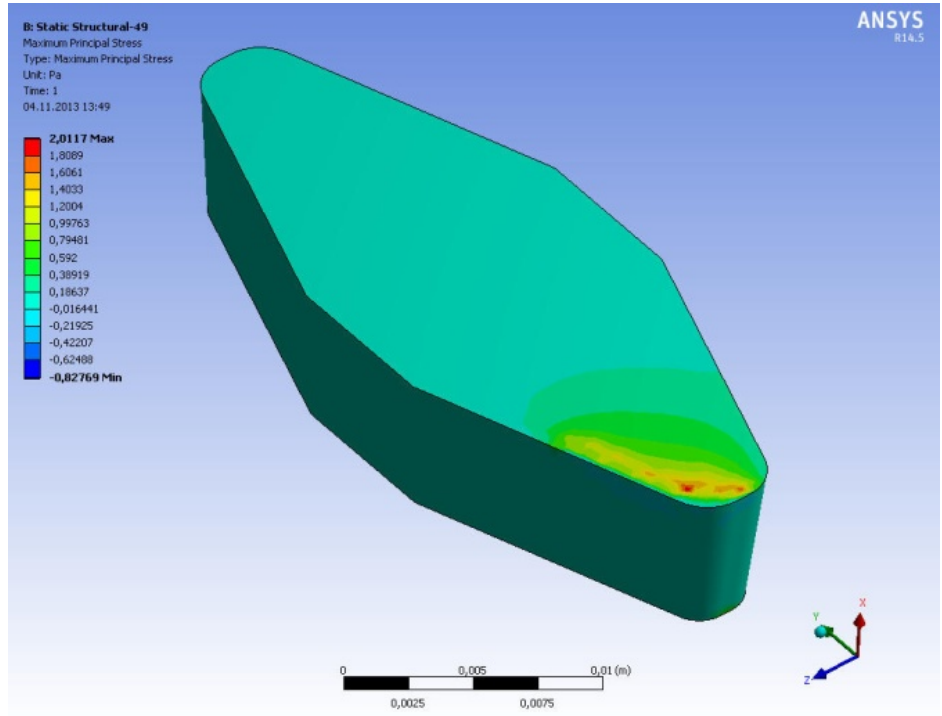

a)

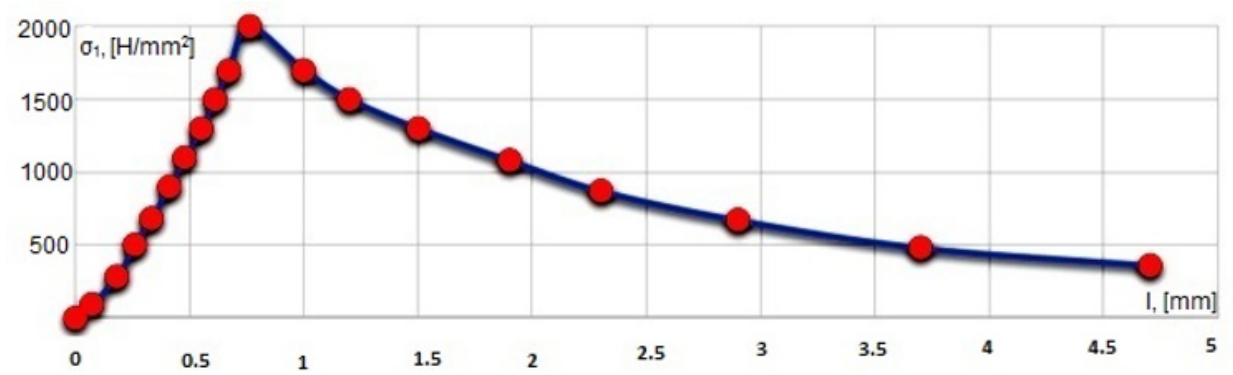

b)

Fig. 3. Pictures of tensile stresses $\sigma 1$ for plates from WC-Co hard alloy from the making rail made on DIN3972:

a) color gradation of tensile stresses $\sigma 1$;

b) schedule of distribution of the main tensile stresses.

In Figure $3 \mathrm{~b}$ it is visible that the stretching tension ${ }_{\sigma 1}$ and curve distributions of the main stretching tension is big. Thereby it characterizes the tool at which are made plates of WCCo hard alloy from the making rail of the work made on DIN3972 by a low resource because of high constraint of cutting.

In Figures 4a, and 5a, the received samples of tension and the chart of distribution of the main tensile stresses for plates with the making rail made according to the progressive scheme of cutting are shown. The analysis of patterns of isolines of distribution of tension ${ }_{\sigma 1}$ in teeths of a mill showed that tensile stresses along a front surface of WC-Co hard alloy decrease because each plate, cuts off the site of the processed material. 


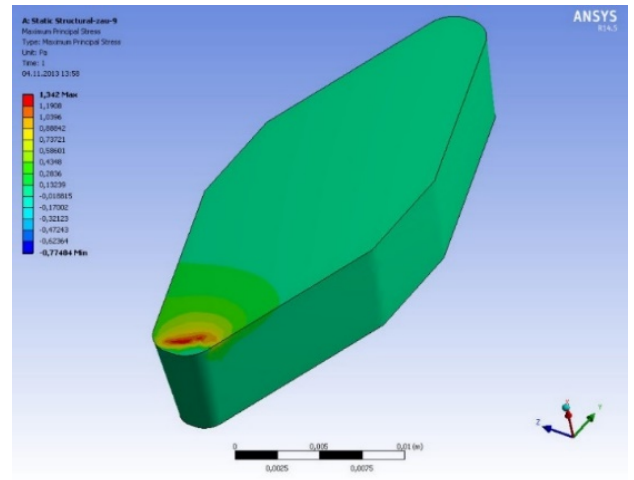

a)

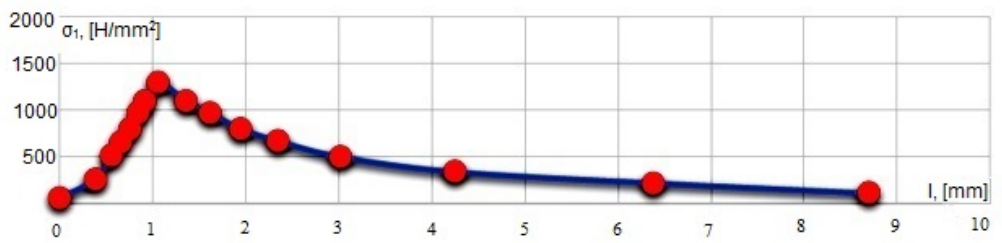

b)

Fig. 4. Pictures of tensile stresses in WC-Co hard alloy with the made narrower contour e1 a) color gradation of tensile stresses $\sigma 1$;

b) schedule of distribution of the main tensile stresses.

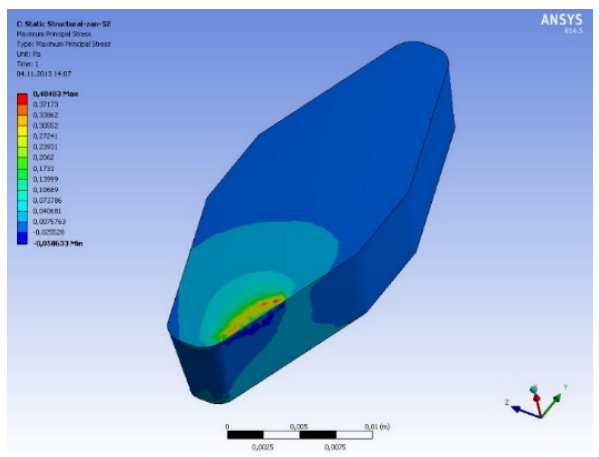

a)

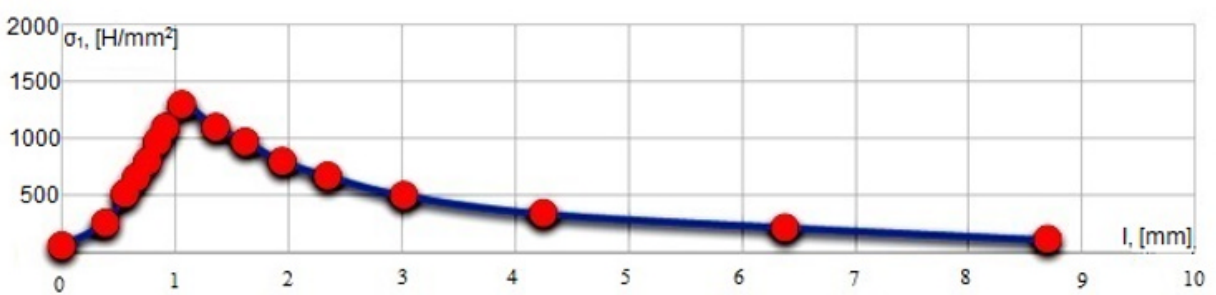

b)

Fig. 5. Pictures of tensile stresses in WC-Co hard alloy with the made narrower contour e2 a) color gradation of tensile stresses $\sigma_{11}$;

b) schedule of distribution of the main tensile stresses. 
It is connected with the fact that at first the cutting plate works with a profile e1 which cuts off the processed material with an upper part of a plate, and then the plate works with a profile e2 which works with the side cutting edges. The analysis showed that in terms of tension the best results at calculation are yielded by the tool with the making rail made according to the progressive scheme of cutting. Thus, the making rail, made according to the progressive scheme of cutting has a great influence on tension in WC-Co hard alloy. Color gradation of the main tension show that all tension is dispersed along all cutting edge evenly, without brightly revealed zones of concentration of tensile stresses. Deformation along the cutting edge is homogeneous, without the expressed jumps. The solution of threedimensional tasks helped to establish that extent of deformation of the main cutting edge is different for plates of a different form.

Research of influence of geometry of the cutting plate from WC-Co hard alloy on their deformed state in the plane of a descent of shaving revealed the following: the plate geometry from WC-Co hard alloy influences distribution of tension in a plate under identical operating conditions of the tool (the cut module, quantity of teeths of a wheel and giving of the tool), the greatest deformation are observed on a front surface in the shaving descent plane. It is revealed that the value of tension of stretchings ${ }_{\sigma 1}$ in a plate from WCCo hard alloy of teeths of a mill from the making rail made on DIN3972 several times is more, than at with the making rail made according to the progressive scheme of cutting that, allows to increase processing speed. As modeling took place under the same conditions of processing, for the progressive scheme of cutting it is possible to increase the processing cutting modes. During the work of a mill with the progressive scheme of cutting the tangential component of force of cutting is much less, than from a standard mill. At design of worm mills with replaceable hard-alloy plates it is necessary to consider the module of the cut wheel since with increase in the module cross-section of the cut-off layer increases. With growth of the cut module width of a cut and thickness grows.

\section{References}

1. Zhonghe Y, Zhaohui L, Smith MR. Mechanisms and machine theory. Beijing, China: High Education Press, 2001.

2. W. Liu, D. Ren, S. Usui, J. Wadell, T. D. Marusich, A gear cutting predictive model using the finite element method, J. CIRP. 8 (2013) pp 51-56.

3. M. S. Ostapenko, D. S. Vasilega, Method of evaluation of quality of metal-cutting tool, J. Appl. Mech. Mater. 379 (2013) pp 49-55.

4. E. V. Artamonov, D. V. Vasil'ev, Determining the optimal cutting speed in turning by composite cutters on the basis of the chip, J. Russ. Eng. Res. 34(6) (2014) 404-405.

5. E. V. Artamonov, V. V. Kireev, Effectiveness of cutting by hods with replaceable hardalloy plates, J. Russ. Eng. Res. 37(7) (2014) pp 473-474.

6. E. V. Artamonov, D. S. Vasilega, A. M. Tveryakov, Determining the maximumperformance temperature of hard-alloy cutting plates, J. Russ. Eng. Res. 34(6) (2014) pp 402-403.

7. D. S. Vasilega, M. S. Ostapenko, Efficiency improvement of metal lathing by using of an evaluation technique of abembly machine tools quality, Key Eng. Mater. 684 (2016) pp 421-428.

8. M. S. Ostapenko, D. S. Vasilega, An industrial and sociological research of consumers requirements to a lathing tool, Key Eng. Mater. 684 (2016) pp 429-434. 
9. S. Steina, M. Lechthalera, S. Krassnitzera, K. Albrechta, A. Schindlerb, M. Arndta, Gear hobbing: A contribution to analogy testing and its wear mechanisms, J. CIRP. 1(1) (2012) 220-225.

10. T. Tokawa, Y. Nishimura, Y. Nakamura, High productivity dry hobbing system, J. Mitsubishi Heavy Ind. 38(1) (2001) pp 27-31.

11. B. Karpuschewski, H.-J. Knoche, M. Hipke, M. Beutner, High performance gear hobbing with powder-metallurgical high-speed-steel, J. CIRP. 1(1) (2012) pp 196-201.

12. G. Hyatt, M. Piber, N. Chaphalkar, O. Kleinhenz, M. Mori, A review of new strategies for gear production, J. CIRP. 14 (2014) pp 72-76.

13. S. Xu and Y. Zhang, The Finite Element Modeling and Analysis of Involute Spur Gear, Advanced Materials Research, Vols. 516-517, pp 673-677, 2012

14. Kanber Bahattin. Analysis of Spur Gears by Coupling Finite and Boundary Element Methods. Mechanics based design of structures and machines, 2006 Volume 34, Issue 3, pp 307-324.

15. Forte, Paola; Paoli, Alessandro; Razionale, Armando Viviano. A CAE approach for the stress analysis of gear models by $3 D$ digital photoelasticity. International journal of interactive design and manufacturing, February 2015, Volume 9, Issue 1, pp 31-43.

16. E. V. Artamonov, V. V. Kireev, The Compound Hob For Processing Gearbox Pinions Used In Hoist For Well Repairs, Appl. Mech. Mater. 770 (2015) pp 469-475.

17. Artamonov E.V., Kireev V.V., Zyryanov V.A., An interlocking side mill with retrofittable carbide blades for processing of coarse-pitch tooth wheels, MATEC Web of Conferences 224. ICMTMTE - 2018. pp. 1-5. (2018)

18. X. DongC. Liao, Y.C. Shin, H.H. Zhang. Machinability improvement of gear hobbing via process simulation and tool wear predictions, October 2016, Volume 86, Issue 912, pp 2771-2779.

19. N. Srinivasan, M. S. Shunmugam. Limiting conditions in gear shaping for corrected involute gears, International Journal of Machine Tool Design and Research. Volume 23, Issue 4, 1983, pp 227-235. 